\title{
PENERAPAN METODE ANALYTICAL HIERARCHY PROCESS DAN PREFERENCE RANKING ORGANIZATION METHOD FOR ENRICHMENT EVALUATION UNTUK PEMILIHAN MITRA TERBAIK PADA PT MNG
}

\author{
Nurcholis Ali Sya'bana \\ Program Studi Teknik Informatika, Fakultas Teknik, Universitas Muhammadiyah Tangerang \\ Jl. Perintis Kemerdekaan 1/33 Cikokol Kota Tangerang \\ Co Responden Email: nurcholisali1@gmail.com
}

\section{Article history \\ Received Des 08, 2020 \\ Revised Feb 12, 2021 \\ Accepted Feb 23, 2021 \\ Available online Feb 27, 2021 \\ Keywords \\ Sistem Pendukung Keputusan, AHP, PROMETHEE, Mitra}

Riwayat

Diterima 08 Des 2020

Revisi 12 Des 2021

Disetujui 23 Feb 2021

Terbit 27 Feb 2021

Kata Kunci

Sistem Pendukung Keputusan, AHP, PROMETHEE, Mitra
Abstract

Partners are one of the parts that play a very important role for the running of a company in the production process in order to become goods as needed. PT MUTIARA NUSANTARA GLOBALINDO (MNG) is one of the manufacturing companies engaged in garments that has many partners. Partner performance assessment is one of the keys for the production process to run to the maximum. The problem in partner performance assessment is that it is still difficult to determine the best partner, because the criteria used in partner selection have not been up to standard. Assessment has not used the right method in determining it so that the process of processing data becomes unbiased and often mistakes occur. This research aims to develop a partner selection decision support system using Analytical Hierarchy Process (AHP) and Preference Ranking Organization Method for Enrichment Evaluation (PROMETHEE) methods. This study produced weight values on the criteria of Quality $41 \%$ Cost $29 \%$, Delivery $16 \%$, Capacity $8 \%$ and Attitude $6 \%$, with consistency test results ratio of 0.067. Partner selection decision support system designed to assist in conducting easier, faster and more accurate partner assessments.

\footnotetext{
Abstrak

Mitra merupakan salah satu bagian yang memegang peranan yang sangat penting untuk berjalannya suatu perusahaan dalam melakukan proses produksi agar dapat menjadi barang sesuai kebutuhan. PT MUTIARA NUSANTARA GLOBALINDO (MNG) merupakan salah satu perusahan manufaktur yang bergerak di bidang garmen yang memiliki banyak mitra. Penilaian kinerja mitra merupakan salah satu kunci agar proses produksi bisa berjalan dengan maksimal. Masalah yang ada dalam penilaian kinerja mitra adalah masih kesulitan dalam menentukan mitra terbaik, karena kriteria yang digunakan dalam pemilihan mitra belum sesuai standar. Penilaian belum menggunakan metode yang tepat dalam penentuanya sehingga proses pengolahan datanya menjadi tidak objektif dan sering terjadi kesalahan. Penelitian ini bertujuan untuk mengembangkan sebuah sistem pendukung keputusan pemilihan mitra menggunakan metode Analytical Hierarchy Process (AHP) dan Preference Ranking Organization Method for Enrichment Evaluation (PROMETHEE). Penelitian ini menghasilkan nilai bobot pada kriteria Quality $41 \%$ Cost 29\%, Delivery 16\%, Capacity $8 \%$ dan Attitude 6\%, dengan hasil uji konsistensi rasio sebesar 0,067. Sistem Pendukung Keputusan pemilihan mitra yang dirancang dapat membantu dalam melakukan penilaian mitra yang lebih mudah, cepat dan akurat.
} 


\section{PENDAHULUAN}

Perusahaan dalam melakukan kegiatan bisnisnya membutuhkan mitra atau perusahaan lain untuk bekerjasama yang saling meng-untungkan satu sama lain. Pemilihan mitra terbaik adalah salah satu cara untuk mendorong mitra agar terus menjaga produktifitasnya.

Dalam pemilihan mitra PT Mutiara Nusantara Globalindo saat ini mengalami kesulitan dalam menentukan mitra terbaik dikarenakan belum ada kriteria yang standar serta metode yang tepat dalam penilaian kinerja mitra setiap bulanya. Sehingga masih tinggi subyektifitas dalam pemilihan mitra setiap bulan ya.

Studi mengenai system pen- dukung keputusan pemilihan mitra menggunakan metode SAW telah dilakukan oleh [1], metode SAW dan TOPSIS oleh [2]. Metode Multi-kriteria oleh [3]. Dari penelitian terdahulu masih belum ada yang menggunakan kombinasi metode AHP dan PROMETHEE dalam pemilihan mitra.

Penelitian ini bertujuan untuk mengembangkan sebuah model sistem pendukung keputusan yang dapat membantu PT MNG dalam melakukan pemilihan mitra meng-gunakan metode AHP dalam menentukan bobot kriteria dan metode PROMETHEE untuk penentuan rangking mitra terbaik berdasarkan perhitungan masing-masing kriteria.

Penelitian ini diharapkan dapat membantu PT MNG dalam pemilihan mitra terbaik yang lebih cepat, akurat dan obyektif sesuai dengan kriteria - kriteria yang telah ditetapkan.

\section{METODE PENELITIAN Langkah Langkah Penelitian}

Berikut merupakan langkah-langkah penelitian yang dilakukan

Mulai

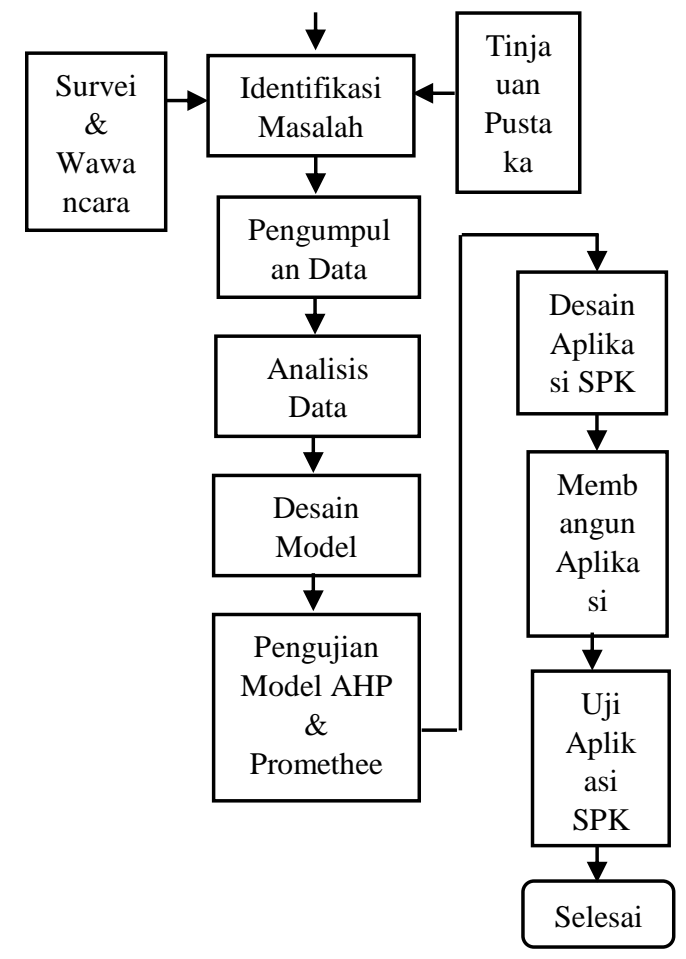

Gambar II- 1 Tahapan Penelitian

1) Identifikasi Masalah identifikasi masalah dengan tinjauan pustaka yaitu dengan mempelajari, meneliti, dan membaca jurnal, buku, dan informasi dari internet yang berhubungan dengan masalah yang diteliti serta wawancara ke tempat penelitian dengan pihak yang berkaitan.

2) Pengumpulan Data

Pengumpulan data dititikberatkan ke bagian Production Planning Control, Procurement dan quality control.

3) Analisa Data

Menganalisa hasil dari pe-ngumpulan data yang berkaitan dengan pemilihan mitra seperta report, Rekap Order dll.

4) Desain Model

Menentukan metode SPK dengan cara memilih metode yang tepat untuk pemilihan Mitra. Berdasarkan krirteria - kriteria yang diberikan maka metode AHP digunakan untuk penentuan bobot dan Promethee 
dipilih untuk penentuan ranking kinerja mitra.

5) Pengujian Metode AHP dan Promethee

Dilakukan dengan cara meng- hitung Consistency Ratio dari hasil perhitungan bobot meng-gunakan metode AHP dengan ketentuan jika nilainya lebih dari 0,1 , maka penilaian judgement harus diperbaiki. Namun jika rasio konsistensi kurang atau sama dengan 0,1 , maka hasil perhitungan bisa dinyatakan benar. Selanjutnya dilakukan perhitungan metode Promethe dengan menghitung Total Indeks Preferensi, nilai leaving Flow, Entering Flow dan Net Flow.

6) Desain Aplikasi SPK

Dilakukan dengan merancang model aplikasi SPK pemilihan mitra yang terdiri dari rancangan kebutuhan sistem menggunakan use case diagram dan rancangan layar.

7) Membangun Aplikasi SPK dengan membangun prototype SPK pemilihan mitra dengan menggunakan bahasa pem-rograman PHP dan MySQL.

\section{Analytical Hirarchy Process (AHP)}

Proses pengambilan keputusan pada dasarnya adalah memilih suatu alternatif. Peralatan utama Analytical Hierarchy Process (AHP) adalah sebuah hirarki fungsional dengan input utamanya persepsi manusia. Dengan hirarki, suatu masalah kompleks dan tidak terstruktur dipecahkan ke dalam kelompokkelompoknya. Kemudian kelompokkelompok tersebut diatur menjadi suatu bentuk hirarki.

Analytical Hirarchy Process (AHP) atau Proses Hirarki Analitik adalah suatu perangkat untuk pengambilan keputusan. Bentuknya sederhana, fleksibel dan berdaya guna besar (powerfull) untuk mendukung suatu proses pengambilan keputusan dengan multi kriteria, multi tujuan dan penuh dengan situasi kompleks.

1) Penyusunan Hierarki

Persoalan yang akan diselesaikan, diuraikan menjadi unsur-unsur nya, yaitu kriteria dan alternatif, kemudian disusun menjadi struktur hierarki.

2) Penilaian Kriteria dan Alternatif Untuk membuat pairwise comparison, Prof Saaty membuat skala perbandingan yang disebutnya sebagai skala fundamental yang diturunkan berdasarkan riset psikologis atas kemampuan individu dalam membuat suatu perbandingan secara berpasangan terhadap beberapa elemen yang akan diper-bandingkan. Skala perbandingan terebut adalah sebagai berikut :

Tabel I-1

Skala Perbandingan Berpasangan

\begin{tabular}{|c|l|}
\hline $\begin{array}{c}\text { Intensitas } \\
\text { Kepentingan }\end{array}$ & \multicolumn{1}{|c|}{ Definisi } \\
\hline 1 & $\begin{array}{l}\text { Kedua elemen } \\
\text { pentingnya }\end{array}$ \\
\hline 3 & $\begin{array}{l}\text { Salah satu elemen sedikit } \\
\text { lebih penting }\end{array}$ \\
\hline 5 & $\begin{array}{l}\text { Salah satu elemen jelas lebih } \\
\text { penting }\end{array}$ \\
\hline 7 & $\begin{array}{l}\text { Salah satu elemen } \\
\text { jelas lebih penting }\end{array}$ \\
\hline 9 & $\begin{array}{l}\text { Salah satu elemen paling } \\
\text { penting }\end{array}$ \\
\hline 2.4 .6 .8 & $\begin{array}{l}\text { Apabila ragu-ragu antara dua } \\
\text { nilai yang berdekatan }\end{array}$ \\
\hline
\end{tabular}

3) Penentuan Prioritas

Penentuan prioritas dari matriks pairwise dengan menentukan eigenvector. Caranya yaitu dengan persamaan matematik 3 langkah.

Langkah 1 :

$\mathrm{W}_{i} / \mathrm{W}_{j}=\mathrm{a}_{i j}(\mathrm{i}, \mathrm{j}=1,2, \ldots, \mathrm{n})$

$\mathrm{W}_{i} \quad=$ bobot input dalam baris

$\mathrm{W}_{j} \quad=$ bobot input dalam lajur

Langkah 2 :

$\mathrm{W}_{i}=\mathrm{a}_{i j} \mathrm{~W}_{j}(\mathrm{i}, \mathrm{j}=1,2, \ldots \mathrm{n})$

Untuk kasus-kasus umum mempunyai bentuk : 
$\mathrm{W}_{i}=\frac{1}{n} \sum_{j=i}^{n} a_{i j} w_{j}(\mathrm{i}, \mathrm{j}=1,2, \ldots, \mathrm{n})$

$\mathrm{W}_{i}=$ rataan dari $a_{i 1} w_{1}, \ldots, a_{i n} w_{n}$

Langkah 3 :

Bila perkiraan $\mathrm{a}_{i j}$ baik akan cenderung untuk dekat dengan nisbah $\mathrm{W} i / \mathrm{W}_{j}$. Jika n juga berubah maka $\mathrm{n}$ diubah menjadi $\lambda$ max maka diperoleh :

$\mathrm{W}_{i}=\frac{1}{\lambda \max } \sum_{j=i}^{n} a_{i j} w_{j}(\mathrm{i}=1,2, \ldots, \mathrm{n})$

Selanjutnya pengolahan horizontal untuk menyusun perioritas elemen keputusan setiap tingkat hirarki keputusan. Tahapanya menurut Saaty 1983 adalah sebagai berikut :

Perkalian baris (z) dengan rumus :

$$
Z_{i}=\sqrt[n]{\pi_{j=1}} a_{i j}
$$

Perhitungan vektor prioritas atau vektor eigen :

$$
e V P_{1}=\frac{\sqrt[n]{\frac{n}{\pi} a_{i j}}}{\sum_{i=1}^{n} \sqrt{\prod_{j=i}^{n} a_{i j}}} e V P_{1} \quad \text { adalah }
$$

elemen vektor prioritas ke-i

Perhitungan nilai eigen maksimum

$\mathrm{VA}=\mathrm{a}_{i j} \times \mathrm{VP}$ dengan $\mathrm{VA}=\left(\mathrm{V}_{a i}\right)$

\begin{tabular}{|c|c|}
\hline $\begin{array}{c}\text { Ukuran } \\
\text { Matriks (n) }\end{array}$ & $\begin{array}{c}\text { Indeks } \\
\text { Konsistensi } \\
\text { Acak (RI) }\end{array}$ \\
\hline 1 & 0 \\
\hline 2 & 0 \\
\hline 3 & 0,52 \\
\hline 4 & 0,89 \\
\hline 5 & 1,11 \\
\hline 6 & 1,25 \\
\hline 7 & 1,35 \\
\hline 8 & 1,40 \\
\hline 9 & 1,45 \\
\hline 10 & 1,49 \\
\hline
\end{tabular}

$\mathrm{VB}=\mathrm{VA} / \mathrm{VP}$ dengan $\mathrm{VB}=\left(\mathrm{V}_{b i}\right)$

$$
\begin{aligned}
& \operatorname{Imax}=\frac{1}{n} \sum_{i=1}^{n} a_{i j} \quad \mathrm{VB}_{i} \text { untuk } \mathrm{i}= \\
& 1,2, \ldots, \mathrm{n} \\
& \mathrm{VA}=\mathrm{VB}=\text { vektor antara }
\end{aligned}
$$

4) Perhitungan Index Konsistensi

Pengukuran ini dimaksudkan untuk mengetahui konsistensi jawaban yang berpengaruh kepada kesahihan hasil. Rumusnya sebagai berikut : $C I=\frac{\lambda \max -n}{n-1}$

Untuk mengetahui aapakah CI dengan besaran tertentu cukup baik atau tidak, perlu diketahui rasio yang dianggap baik, yaitu apabila $C R \leq 0.1$. Rumus CR adalah : $C R=\frac{C I}{R I}$

Nilai RI merupakan nilai random indeks yang dikeluarkan oleh oarkridge laboratory yang berupa tabel berikut ini :

Tabel II-1, Nilai Random Index

\section{Promethee (Preference Ranking Organization Methode for Enrichment Evaluation) \\ Preference Ranking Organization} Methode for Enrichment Evaluation (Promethee) merupakan salah satu metode penentuan ranking dalam Multi Criteria Decision Making (MCDM). Promethee adalah suatu metode penentuan urutan (prioritas) dalam analisis multikriteria. Dugaan dari dominasi kriteria yang digunakan dalam Promethee adalah penggunaan nilai dalam hubungan outranking. nilai hubungan outranking berdasarkan pertimbangan dominasi masing - masing kriteria. Indeks preferensi ditentukan dan nilai outranking secara grafis disajikan berdasarkan preferensi dari pembuat keputusan. Data dasar untuk evaluasi dengan metode Promethee disajikan pada Tabel 3 : 
Tabel II-2

Data Dasar Promethee

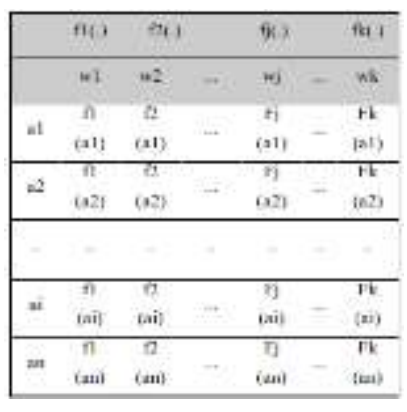

Keterangan :

$a_{1}, a_{2},-a_{n}=n$ alternatif potensial

$f_{1}, f_{2},-f_{1}, f_{k}=k$ kriteria evaluasi.

Struktur preferensil yang dibangun atas dasar kriteria vased ] $f(a)>f(b)=a f b$

$f(a), f(b)\} f(a)=f(b)=a b$

Nilai f merupakan nilai nyata dari suatu kriteria, $\mathrm{f}: \mathrm{K} \rightarrow \boldsymbol{Я}$ (Real Word) dan tujuannya berupa prosedur optimasi untuk setiap alternative yang akan diseleksi, acK, f(a) merupakan evaluasi dari alternatif yang akan diseleksi tersebut untuk setiap kriteria. Penyampaian Intensitas (P) dari preferensi alternatif a terhadap alternatif $\mathrm{b}$ sedemikian rupa Sehingga :

1) $P(a, b)=0$, berarti tidak ada beda antara a dan $\mathrm{b}$ (tidak ada preferensi)

2) $\mathrm{P}(\mathrm{a}, \mathrm{b}) \approx 0$, berarti lemah preferensi dari a lebih baik dari $b$

3) $\mathrm{P}(\mathrm{a}, \mathrm{b})=1$, kuat preferensi dari a lebih baik dari $b$

4) $\mathrm{P}(\mathrm{a}, \mathrm{b}) \approx 1$, berarti muktak preferensi dari a lebih baik dari $b$

Untuk memberikan gambaran yang lebih baik terhadap area yang tidak sama digunakan fungsi selisih nilai kriteria antar alternatif $\mathrm{H}(\mathrm{d})$ dimana hal ini mempunyai hubungan langsung dengan fungsi preferensi $\mathrm{P}$.

Tahapan prosedur untuk pelaksanaan promethee adalah sebagai berikut :

1) Penentuan deviasi berdasarkan perbandingan berpasangan

$d_{j}(a, b)=f\left(a_{j}\right)-f\left(b_{j}\right)$ dimana $j=1,2,3 \ldots, k$

dimana dj(a,b) menunjukan perbedaan antara evaluasi alternative dari a dan $\mathrm{b}$ pada kriteria ke $\mathrm{j}$, dan $\mathrm{k}$ menunjukan kriteria berhingga.

2) Penerapan fungsi preferensi
$P_{f}(a, b)=F\left(d_{i}(a, b)\right)$ dimana $j=1,2, \ldots, k$

dimana $\operatorname{Pj}(a, b)$ sebagai fungsi dj(a,b) menunjukan preferensi alternatif a yang berkaitan dengan alternatif $b$ pada setiap kriteria.

3) Perhitungan indeks preferensi global

$$
\phi(a, b)=\sum_{n=1}^{1} P_{j}(a, b) w_{j}(a, b), \forall a, b \in A
$$

dimana $\varphi(a, b)$ dengan a lebih besar dari $b$ (antara nol hingga satu) didefinisikan sebagai jumlah bobot $\mathrm{P}(\mathrm{a}, \mathrm{b})$ pada setiap kriteria, dan wj adalah bobot yang berhubungan dengan kriteria ke-j.

4) Perhitungan aliran perangkingan dan peringkat parsial

$$
\Phi^{+}=\frac{1}{n-1} \sum_{x \in A} \varphi(a, x)
$$

Dari persamaan di atas, $\phi+($ a) adalah nilai leaving flow pada setiap alternatif a; sedangkan untuk mengitung nilai entering flow-nya atau nilai $\phi$-(a) didapat dari persamaan berikut :

$$
\Phi^{-}=\frac{1}{n-1} \sum_{x \in A} \varphi(x, a)
$$

5) Perhitungan aliran perangkingan bersih dan peringkat lengkap

$\phi(a)=\phi^{+}(a)-\phi^{-}(a)$

dimana $\phi(a)$ adalah net flow, digunakan untuk menghasilkan keputusan akhir penentuan urutan dalam menyelesaikan masalah sehingga menghasilkan urutan lengkap.

\section{Pengujian Sistem}

Technology Acceptance Model merupakan salah satu model yang dibangun untuk menganalisis dan memahami faktor-faktor yang mempengaruhi diterimanya penggunaan teknologi computer. Dalam implementtasi pengujian TAM terdapat beberapa persepsi yang akan menjadi pernyataan atau pertanyaan dalam bentuk kuesioner yang akan diisi oleh pengguna sistem. persepsi tersebut adalah : 
1) Persepsi Kemudahan

2) Aspek Manfaat

3) Aspek Sikap Terhadap Pengguna

4) Aspek Sikap Tujuan Prilaku

Hasil dari kuesioner yang telah diisi oleh pengguna akan hitung sehingga mendapatkan nilai perhitungan akhir yang dapat menyimpulkan apakah sistem dapat diterima oleh pengguna.

\section{HASIL DAN PEMBAHASAN}

\section{Metode AHP}

Berikut langkah langkah pembahasan hasil metode AHP.

\section{- Hirarki dan Tingkat Kepentingan}

Berikut adalah struktur hirarki sistem pendukung keputusan pemilihan mitra dipaparkan pada gambar berikut :

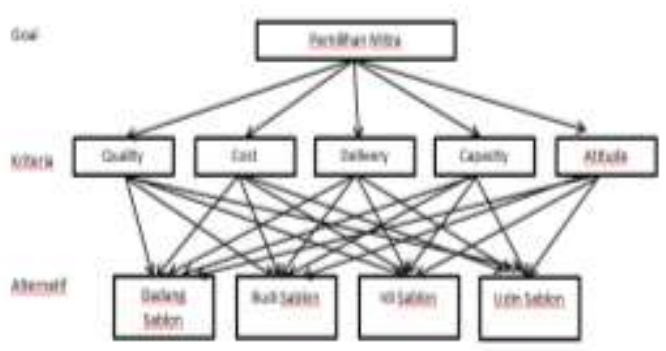

Gambar III-1

- Tahap Pembobotan AHP

Berdasarkan hasil kuesioner yang didapatkan dari responden didapatkan data seperti yang tertera pada tabel berikut.

Tabel III-1 Hasil Responden

\begin{tabular}{|ll|l|l|l|l|}
\hline Krit & $\mathrm{C1}$ & $\mathrm{C} 2$ & $\mathrm{C} 3$ & $\mathrm{C} 4$ & $\mathrm{C5}$ \\
\hline $\mathrm{C} 1$ & 1,00 & 2,00 & 3,00 & 5,00 & 5,00 \\
\hline $\mathrm{C} 2$ & 0,50 & 1,00 & 3,00 & 5,00 & 3,00 \\
\hline $\mathrm{C} 3$ & 0,33 & 0,33 & 1,00 & 3,00 & 3,00 \\
\hline $\mathrm{C} 4$ & 0,20 & 0,20 & 0,33 & 1,00 & 2,00 \\
\hline $\mathrm{C} 5$ & 0,20 & 0,33 & 0,33 & 0,50 & 1,00 \\
\hline iml & 2,33 & 3,86 & 7,66 & 14,50 & 14,00 \\
\hline
\end{tabular}

Tabel III-2 Hasil Normalisasi

\begin{tabular}{|l|l|l|l|l|l|}
\hline Krit & $\mathrm{C1}$ & $\mathrm{C} 2$ & $\mathrm{C} 3$ & $\mathrm{C} 4$ & $\mathrm{C} 5$ \\
\hline $\mathrm{C1}$ & 0.45 & 0.56 & 0.39 & 0.34 & 0.36 \\
\hline $\mathrm{C} 2$ & 0.22 & 0.26 & 0.39 & 0.34 & 0.21 \\
$\mathrm{C} 3$ & 0.15 & 0.09 & 0.13 & 0.21 & 0.21 \\
\hline $\mathrm{C} 4$ & 0.09 & 0.05 & 0.04 & 0.07 & 0.14 \\
\hline $\mathrm{C5}$ & 0.09 & 0.09 & 0.04 & 0.03 & 0.07 \\
\hline $\mathrm{jml}$ & 1 & 1 & 1 & 1 & 1 \\
\hline
\end{tabular}

Setelah diperoleh hasil Normalisai pembagian tiap kolomnya, maka dapat dihitung nilai eigen bobot prioritas dengan persamaan 1 .

Eigen untuk kriteria $\mathrm{C} 1$

$$
\frac{0,448+0,517+0,391+0,345+0,357}{5}=0,412
$$

Selanjutnya dilakukan sampai C5 seperti ditampilkan dalam tabel berikut.

Tabel III.3 Nilai bobot Prioritas

\begin{tabular}{|l|l|}
\hline Kritia & Eigent \\
\hline C1 & 0.41 \\
\hline C2 & 0.29 \\
\hline C3 & 0.16 \\
\hline C4 & 0.08 \\
\hline C5 & 0.06 \\
\hline jml & 1 \\
\hline
\end{tabular}

\section{- Uji Konsistensi}

Selanjutnya Menentukan nilai CI (Consistency Index).

$\lambda$ maksimum $=(2.23 \times 0.412)+(3.86 \mathrm{x}$ $0.287)+(7.66 \times 0.157)+(14.50 \times 0.08)$ $+(14.00 \times 0.065)=5.299$

$$
\mathrm{CI}=\frac{5,399-5}{5-1}
$$

$=0,075$

Pengujian konsistensi diukur menggunakan nilai CR (Consistency Ratio), yaitu perbandingan antara nilai CI dan RI, dimana nilai RI (Random Index). Sehingga didapat-kan nilai CR yaitu :

$$
\begin{aligned}
C R & =\frac{0,01}{1,12} \\
& =0,067
\end{aligned}
$$


Hasil CR $<0.1$ maka dinyatakan konsisten dan dapat diterima.

\section{Metode PROMETHEE}

Metode Promethee digunakan untuk perangkingan mitra dengan nilai yang diberikan untuk masing masing kriteria sudah ditentukan berdasarkan hasil wawancara, bobot prioritas juga didapatkan dari perhitungan sebelum nya melalui metode AHP.

\section{- Menghitung Nilai Preferensi dan Index Preferensi}

Menghitung nilai preferensi $(\mathrm{P})$ dan index preferensi (IP) dengan cara perbandingan nilai tiap kriteria sehingga akan didapat selisih $\mathrm{H}(\mathrm{d})$ dari kriteria dan index preferensi.

Tabel III.4 Total Index Preferensi

\begin{tabular}{|c|c|c|}
\hline \multicolumn{2}{|c|}{ Alternatif } & Total \\
\hline $\mathrm{A} 1$ & $\mathrm{~A} 2$ & 0.1433 \\
\hline $\mathrm{A} 1$ & $\mathrm{~A} 3$ & 0 \\
\hline $\mathrm{A} 1$ & $\mathrm{~A} 4$ & 0 \\
\hline $\mathrm{A} 2$ & $\mathrm{~A} 1$ & 0.4767 \\
\hline $\mathrm{A} 2$ & $\mathrm{~A} 3$ & 0.2383 \\
\hline $\mathrm{A} 2$ & $\mathrm{~A} 4$ & 0.4117 \\
\hline $\mathrm{A} 3$ & $\mathrm{~A} 1$ & 0.2383 \\
\hline $\mathrm{A} 3$ & $\mathrm{~A} 2$ & 0 \\
\hline $\mathrm{A} 3$ & $\mathrm{~A} 4$ & 0.3639 \\
\hline $\mathrm{A} 4$ & $\mathrm{~A} 1$ & 0 \\
\hline $\mathrm{A} 4$ & $\mathrm{~A} 2$ & 0.0325 \\
\hline $\mathrm{A} 4$ & $\mathrm{~A} 3$ & 0.065 \\
\hline
\end{tabular}

\section{- Menghitung Leaving Flow}

Leaving Flow, digunakan untuk menentukan urutan prioritas yang menggunakan urutan parsial dengan perhitungan sebagai berikut :

Leaving flow: $\Phi(\mathrm{a})=\ln _{\mathrm{n}-1} \frac{\sum \delta(\mathrm{a}, \mathrm{x})}{\mathbf{x} \mathbf{A}}$

$\mathrm{A} 1=1 /(4-1) *(0+0.1433+0+0)=$ $0.3333 * 0.1433=0.0478$

$\mathrm{A} 2=1 /(4-1) *(0.4767+0+0.2383+04117)=$

$0.3333 * 0.1267=0.3756$

$\mathrm{A} 3=1 /(4-1) *(0.2383+0+0+0.3693)=$

$0.3333 * 0.6022=0.2007$
$\mathrm{A} 4=1 /(4-1) *(0+0.325+0.065+0)=$ $0.3333 * 0.0975=0.0325$

\section{- Menghitung Entering Flow}

Selain leaving flow, untuk menentukan urutan prioritas juga digunakan perhitungan entering flow dengan perhitungan sebagai berikut :

Entering flow: $\Phi(\mathrm{a})={ }_{\mathrm{n}-1}^{1} \frac{\sum \delta(\mathrm{x}, \mathrm{a})}{\mathbf{x} \varepsilon \mathbf{A}}$

$\mathrm{A} 1=1 /(4-1) *(0+0.4767+0.2383+0)=$ $0.3333 * 0.715=0.2383$

$\mathrm{A} 2=1 /(4-1) *(0.1433+0+0+0.0325)=$ $0.3333 * 0.1758=0.0586$

$\mathrm{A} 3=1 /(4-1) *(0+0.2383+0+0.065)=$ $0.3333 * 0.3034=0.1011$

$\mathrm{A} 4=1 /(4-1) *(0+0.4117+0.3639+0)=$ $0.3333 * 0.7755=0.2585$

\section{- Menghitung Net Flow}

Net Flow Digunakan untuk menghasilkan keputusan akhir penentuan urutan dalam menyelesaikan masalah sehingga menghasilkan urutan lengkap. Net flow $: \Phi(\mathrm{a})=\Phi($ (a) $-\Phi$ (a)

Net Flow : Leaving Flow - Entering Flow

$$
\begin{aligned}
& \text { A1 }=0.0478-0.2383=-0.1906 \\
& \text { A2 }=0.3756-0.0586=0.317 \\
& \text { A3 }=0.2007-0.1011=0.0996 \\
& \text { A4 }=0.0325-0.2585=-0.226
\end{aligned}
$$

\section{Pengujian Sistem}

Pengujian kemampuan sistem dilakukan menggunakan kuesioner dengan Technology Acceptance Model (TAM) untuk memperoleh hasil output dalam sebuah bentuk dokumen hasil uji yang dapat dijadikan bukti bahwa software sudah diterima. Berikut ini adalah hasil pengujian TAM yang telah dilakukan

- Presentase Aspek Persepsi Kemudahan (Perceived Easy of Use) 


\begin{tabular}{|c|c|c|c|c|c|c|}
\hline $\begin{array}{l}\text { Jawa } \\
\text { ban }\end{array}$ & $\begin{array}{c}\text { Bob } \\
\text { ot }\end{array}$ & 1 & 2 & 3 & 4 & $\begin{array}{l}\text { Tot } \\
\text { al }\end{array}$ \\
\hline SS & 5 & 3 & 3 & 2 & 3 & 11 \\
\hline $\mathrm{S}$ & 4 & 1 & 1 & 2 & 1 & 5 \\
\hline CS & 3 & 0 & 0 & 0 & 0 & 0 \\
\hline TS & 2 & 0 & 0 & 0 & 0 & 0 \\
\hline STS & 1 & 0 & 0 & 0 & 0 & 0 \\
\hline \multicolumn{2}{|c|}{$\begin{array}{c}\text { Jumlah } \\
\text { Responden }\end{array}$} & 4 & 4 & 4 & 4 & 16 \\
\hline \multicolumn{2}{|c|}{ Skor Aktual } & $\begin{array}{l}1 \\
9 \\
\end{array}$ & $\begin{array}{l}1 \\
9 \\
\end{array}$ & $\begin{array}{l}1 \\
8 \\
\end{array}$ & $\begin{array}{l}2 \\
0 \\
\end{array}$ & 76 \\
\hline \multicolumn{2}{|c|}{ Skor Ideal } & $\begin{array}{l}2 \\
0\end{array}$ & $\begin{array}{l}2 \\
0\end{array}$ & $\begin{array}{l}2 \\
0\end{array}$ & $\begin{array}{l}2 \\
0\end{array}$ & 80 \\
\hline
\end{tabular}

Tabel diatas merupakan hasil penilaian kuesioner dengan hasil skor aktual sebagai berikut :

$$
\begin{aligned}
& \% \text { Skor Aktual }=\frac{\text { Skor aktual }}{\text { Skor ideal }} \\
& \% \text { Skor Aktual }=\frac{76}{80} \times 100 \% \\
& \% \text { Skor Aktual }=95 \%
\end{aligned}
$$

\begin{tabular}{|c|c|c|c|c|c|c|}
\hline $\begin{array}{c}\text { Jawa } \\
\text { ban }\end{array}$ & $\begin{array}{c}\text { Bob } \\
\text { ot }\end{array}$ & 1 & 2 & 3 & 4 & $\begin{array}{c}\text { Tot } \\
\text { al }\end{array}$ \\
\hline SS & 5 & 3 & 0 & 3 & 0 & 6 \\
\hline $\mathrm{S}$ & 4 & 0 & 2 & 1 & 4 & 7 \\
\hline $\mathrm{CS}$ & 3 & 1 & 2 & 0 & 0 & 3 \\
\hline TS & 2 & 0 & 0 & 0 & 0 & 0 \\
\hline STS & 1 & 0 & 0 & 0 & 0 & 0 \\
\hline \multicolumn{2}{|c|}{$\begin{array}{c}\text { Jumlah } \\
\text { Responden }\end{array}$} & 4 & 4 & 4 & 4 & 16 \\
\hline \multicolumn{2}{|c|}{ Skor Aktual } & $\begin{array}{l}1 \\
8\end{array}$ & $\begin{array}{l}1 \\
4\end{array}$ & $\begin{array}{l}1 \\
9\end{array}$ & $\begin{array}{l}1 \\
6\end{array}$ & 67 \\
\hline \multicolumn{2}{|c|}{ Skor Ideal } & $\begin{array}{l}2 \\
0\end{array}$ & $\begin{array}{l}2 \\
0\end{array}$ & $\begin{array}{l}2 \\
0\end{array}$ & $\begin{array}{l}2 \\
0\end{array}$ & 80 \\
\hline
\end{tabular}

- Persentase Aspek Manfaat (Percevied Usefulness)

dengan hasil skor aktual sebagai

berikut :

$\%$ Skor Aktual $=\frac{67}{80} \quad \times 100 \%$

$\%$ Skor Aktual $=84 \%$

- Persentase Aspek Persepsi Sikap Terhadap Penggunaan (Attitude Toward Using)

\begin{tabular}{|c|c|c|c|c|c|c|}
\hline $\begin{array}{c}\text { Jawa } \\
\text { ban }\end{array}$ & $\begin{array}{c}\text { Bo } \\
\text { bot }\end{array}$ & 1 & 2 & 3 & 4 & $\begin{array}{c}\text { To } \\
\text { tal }\end{array}$ \\
\hline SS & 5 & 3 & 2 & 0 & 0 & 5 \\
\hline S & 4 & 1 & 2 & 2 & 2 & 7 \\
\hline CS & 3 & 0 & 0 & 2 & 2 & 4 \\
\hline TS & 2 & 0 & 0 & 0 & 0 & 0 \\
\hline STS & 1 & 0 & 0 & 0 & 0 & 0 \\
\hline
\end{tabular}

\begin{tabular}{|c|c|c|c|c|c|}
\hline $\begin{array}{c}\text { Jumlah } \\
\text { Responden }\end{array}$ & 4 & 4 & 4 & 4 & 16 \\
\hline Skor Aktual & 1 & 1 & 1 & 1 & 65 \\
& 9 & 8 & 4 & 4 & \\
\hline Skor Ideal & 2 & 2 & 2 & 2 & 80 \\
& 0 & 0 & 0 & 0 & \\
\hline
\end{tabular}

$\%$ Skor Aktual $=6 \underline{5}$

$$
\frac{65}{80} \quad X 100 \%
$$

$\%$ Skor Aktual $=81 \%$

- Persentase Aspek Persepsi Tujuan Perilaku (Behavioral Intention To Use)

\begin{tabular}{|c|c|c|c|c|}
\hline Jawaban & Bobot & 1 & 2 & Total \\
\hline SS & 5 & 1 & 3 & 4 \\
\hline S & 4 & 3 & 1 & 4 \\
\hline CS & 3 & 0 & 0 & 0 \\
\hline TS & 2 & 0 & 0 & 0 \\
\hline STS & 1 & 0 & 0 & 0 \\
\hline \multicolumn{2}{|r|}{ Jumlah Responden } & 4 & 4 & 8 \\
\hline \multicolumn{2}{|r|}{ Skor Aktual } & 17 & 19 & 36 \\
\hline \multicolumn{2}{|l|}{ Skor Ideal } & 20 & 20 & 40 \\
\hline
\end{tabular}

$$
\% \text { Skor Aktual }=\frac{36}{40} \quad \mathrm{X} 100 \%
$$$$
\% \text { Skor Aktual }=90 \%
$$

- Kesimpulan Pengujian Technology Acceptance Model (TAM)

\begin{tabular}{|c|l|l|l|l|}
\hline No & \multicolumn{1}{|c|}{ Aspek } & $\begin{array}{c}\text { Skor } \\
\text { Aktual }\end{array}$ & $\begin{array}{c}\text { Skor } \\
\text { Ideal }\end{array}$ & $\begin{array}{c}\text { Total } \\
\text { Skor }\end{array}$ \\
\hline 1 & $\begin{array}{l}\text { Persepsi } \\
\text { Kemudahan }\end{array}$ & 76 & 80 & $95 \%$ \\
\hline 2 & $\begin{array}{l}\text { Persepsi } \\
\text { Manfaat }\end{array}$ & 67 & 80 & $83.7 \%$ \\
\hline 3 & $\begin{array}{l}\text { Persepsi } \\
\text { Sikap } \\
\text { Terhadap } \\
\text { Penggunaan }\end{array}$ & 65 & 80 & $81.2 \%$ \\
\hline 4 & $\begin{array}{l}\text { Persepsi } \\
\text { Tujuan } \\
\text { Perilaku }\end{array}$ & 36 & 40 & $90 \%$ \\
\hline & \multicolumn{2}{|l}{} & & \\
\hline
\end{tabular}

\section{KESIMPULAN}

Sistem Pendukung Keputusan dengan metode AHP dan PROMETHEE dapat memilih mitra terbaik dengan cepat, tepat, akurat dan lebih obyektif, sesuai dengan kriteria yang ditetapkan PT.MNG. Hasil pengujian model sistem pendukung keputusan menggunakan uji konsistensi rasio 
(Consistensy Ratio) terhadap kriteria pemilihan mitra menghasilkan nilai CR sebesar 0.06 sehingga dapat dinyatakan konsisten. Hasil Pengujian software berdasarkan 4 variable model TAM secara keseluruhan menunjukan aplikasi ini dapat diterima dengan baik oleh pengguna yaitu sebesar $86,2 \%$.

\section{REFERENSI}

ades galih anto, dkk November 2015."Sistem Pendukung

Keputusan Penilaian Kinerja Karyawan Menggunakan Metode SAW (Simple Additive Weighting)" journal Vol. III No. 4november 2015. Purwokerto : Universitas Muhammadiyah Purwokerto.

Hamzah denny subagyo, dkk. 2017.“Analisa Sistem Penunjang Keputusan Penilaian Kinerja Karyawan Dengan Metode Simple Additive Weighting Berbasis Android" journal Vol. 26 No. 2September 2017. Surabaya:

Universitas Narotama

Mauidzoh, U dan Zabidi, Y. 2007. Perancangan Sistem Penilaian dan Seleksi Supplier Menggunakan Multikriteria. Jurnal Ilmiah Teknik Industri (JITI) UMS, 5(3).

Pramudyo, C.S dan Purnomo, E.H. 2012. Perancangan Sistem Pendukung Keputusan untuk Pemilihan Pemasok Nata De Coco dengan Metode Simple Additive Weighting $(S A W)$. Jurnal Ilmiah Teknik Industri (JITI)UMS, 11(1)
Putri, L.S., Hidayat, N dan Suprapto. 2018. Sistem Pendukung Keputusan Pemilihan Mitra Jasa Pengiriman Barang menggunakan Metode Simple Additive Weighting (SAW) - Technique for Other Reference by Similarity to Ideal Solution (TOPSIS) di Kota Malang. Jurnal Pengembangan Teknologi informasi dan Ilmu Komputer (JPTIIK), 3(2).

R. A. Suherdi, R. Taufiq, A. A. Permana. "Penerapan Metode AHP dalam Sistem Pendukung Keputusan Kenaikan Pangkat Pegawai Di Badan Kepegawaian Dan Pengembagan Sumber Daya Manusia Kota Tangerang," in SINTAK, 2018, pp. 522-528.

Subhan akbar wakanda, dkk. 2016."Sistem Pendukung Keputusan Penilaian Kinerja Karyawan Menggunakan Metode Multifactor Evaluation Process" journal Vol. 2 No. 1-juni 2016. Kendari: Universitas Halu Oleo. 